\title{
Integrated Silicon-Polymer Laterally Stacked Bender for Sensing Microgrippers
}

\author{
T. Chu Duc, J. Wei and P. M. Sarro \\ Delft Institute for Micro-Electronics and \\ Submicrontechnology, DIMES \\ Delft University of Technology, TU Delft \\ Delft, the Netherlands \\ Email: t.chuduc@tudelft.nl
}

\author{
G. K. Lau \\ Department of Precision and Microsystems \\ Engineering, Faculty of 3ME, \\ Delft University of Technology, TU Delft \\ Delft, the Netherlands \\ Email: g.lau@3me.tudelft.nl
}

\begin{abstract}
This paper presents a novel electro-thermal microgripper based on integrated silicon-polymer laterally stacked microactuators. The device consists of a serpentineshape deep silicon structure with a thin film aluminum heater on the top and filling polymer in the trenches among the vertical silicon parts. The fabrication is based on deep reactive ion etching of silicon, aluminum sputtering and SU8 filling. The actuator is $500 \mu \mathrm{m}$ long, $65 \mu \mathrm{m}$ wide and $50 \mu \mathrm{m}$ high. The microgripper generates a large motion up to $52 \mu \mathrm{m}$ at a driving voltage of only $2 \mathrm{~V}$ and with a power consumption of $50 \mathrm{~mW}$. The maximum working temperature is $164^{\circ} \mathrm{C}$ at $2 \mathrm{~V}$.
\end{abstract}

\section{INTRODUCTION}

The development of microtools for handling and manipulating particles or small components has become a great technological challenge. There is a high demand for microgrippers with a large motion grasping force. Microgrippers based on polymer and silicon are particularly interesting for single cell manipulation and positioning, cell separation, minimally invasive and living cells surgery, microrobotics and microassembly.

Various microactuators such as piezoelectric [1,2], electrostatic [3], and electro-thermal [4,5,6,7] are developed using MEMS technology for microgripper applications. Generally, electro-thermal actuators are preferred as they require lower driving voltages. Especially the polymeric electro-thermal microgrippers have been widely investigated as they are capable of producing larger displacements at a lower driving voltage and operating temperature $[5,6,7]$. However, most of the developed polymeric microgrippers employ two-material structures. The metal heater is deposited on the top of a high thermal expansion coefficient polymer layer. The structures are bent when heated. The interface between the heat source and the polymer layer is rather limited by the surface area of the metal layer and the heat transfer along the vertical dimension is not effective. Since the polymer layers have low thermal conductivity, the reported structures $[5,6]$ have limited movement. Moreover, the unintended vertical movement couples and interferes with the desired lateral movement $[5,6]$.

This paper presents novel electro-thermal integrated silicon-polymer laterally stacked microactuators. The device is based on a three-material composite: a metal heating layer, a silicon structure as frame and heat conducting environment and a polymer with a high thermal expansion efficient (CTE). During actuation, heat is efficiently transferred from the heater to the polymer by employing the high thermal conduction of the deep silicon serpentine structures that have a large interface with the surrounding polymer. This design overcomes the above mentioned weaknesses of the other designs and it boasts a large lateral jaw movement with a low coupled vertical motion. The device is made on regular silicon wafers with a fabrication process compatible with CMOS technology. Moreover, a sensing microgripper can be fabricated by combining this structure with a lateral force sensing cantilever [8]. Sensing microgrippers are required in assays where feedback force is needed.

\section{DESIGN}

To realize the proposed device SU8-2002 polymer has been selected. This is an epoxy-type photo-patternable polymer with a large coefficient of thermal expansion (CTE) of $52 \mathrm{ppm} /{ }^{\circ} \mathrm{C}$ [9], a Young's modulus of $4.95 \mathrm{GPa}$ [10] and glass transition temperature above $200{ }^{\circ} \mathrm{C}$ [9]. Moreover, Ref. 11 shows that SU8 is a good biocompatible material. These properties make SU8 a suitable material for electrothermal microactuators, especially for building tools for biomedical research.

Fig. 1a shows the sketch of an electro-thermal siliconpolymer laterally stacked microgripper. The microgripper is designed for normally opened operation mode. Each actuator has a serpentine-shape deep silicon structure with a thin-film metal heater layer on the top. The silicon structure is embedded in the SU8 polymer.

This work is partly sponsored by the Vietnamese Ministry of

Education and Training 
Fig. 1b shows the constrained polymer between two parallel rigid silicon plates. The silicon structures are surrounded by the SU8 polymer. Instead of transferring heat directly from the heater to the polymer as in the case of other designs $[5,6]$, the efficient distribution of the heat to the polymer occurs through the large interface areas between the silicon structure and the polymer. Consequently, the stacks expand along the lateral direction.

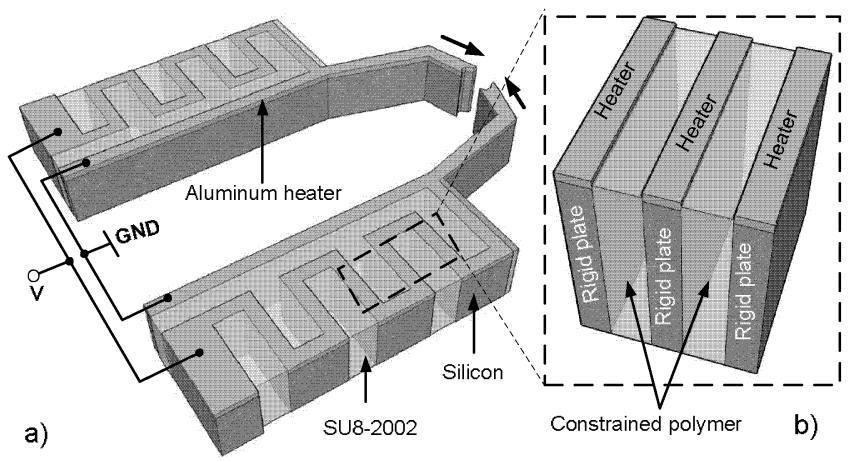

Figure 1. Sketch of a) the electro-thermal integrated silicon-polymer laterally stacked microgripper and b) constrained polymer between two rigid plates.

The unimorph actuators are constructed by combining the constrained polymer stack and the bone cantilever (see Fig. 1a). When a voltage is applied to the heater the polymer stacks expand along the lateral direction while the length of the silicon bone is not changed. Hence, the unimorph actuators bend.

\section{FABRICATION}

The electro-thermal integrated silicon-polymer laterally stacked microgripper is fabricated using a three-mask process. It can be divided in four major parts as schematically shown in Fig. 2.

The substrate is a p-type Si wafer on which a LPCVD silicon nitride layer is deposited as the back side masking layer for the anisotropic wet etching of the silicon bulk. On the wafer front side a $600 \mathrm{~nm}$ thick aluminum and a $2 \mu \mathrm{m}$ thick PECVD silicon oxide are deposited and patterned by reactive ions etching (RIE) to define the serpentine aluminum heaters (see Fig. 2a).

In Fig. $2 b$, the $50 \mu \mathrm{m}$ deep silicon trenches are created by deep reactive ion etching. Due to the characteristics of the deep RIE, i.e. the etch rate is faster on larger windows than smaller ones, the outside areas are deeper than the small trenches (see Fig. 2b and Fig. 3a). Then the silicon oxide mask layer is removed in buffered hydrofluoric acid solution (BHF 1:7).

Negative photosensitive SU8-2002 polymer is applied on the substrate and after waiting for 5 minutes to allow the polymer to sink into the trenches, the wafer is spun at 400 rpm for 30 seconds. The samples are pre-baked on a temperature controlled hotplate. The hotplate is ramped from room temperature to $65{ }^{\circ} \mathrm{C}$ and $95{ }^{\circ} \mathrm{C}$ and then cooled at constant rate to room temperature, as indicated in Fig. 4. The exposure is done by using a Karl Suss MA6 contact aligner [12] for 60 seconds. The post-bake procedure, also indicated in Fig. 4, is followed by a relaxation step at room temperature for 30 minutes. The resist is developed in SU8 developer for 15 minutes without mechanical oscillation aid flows to prevent deformation or debonding during development (see Fig. 2c and Fig. 3b).

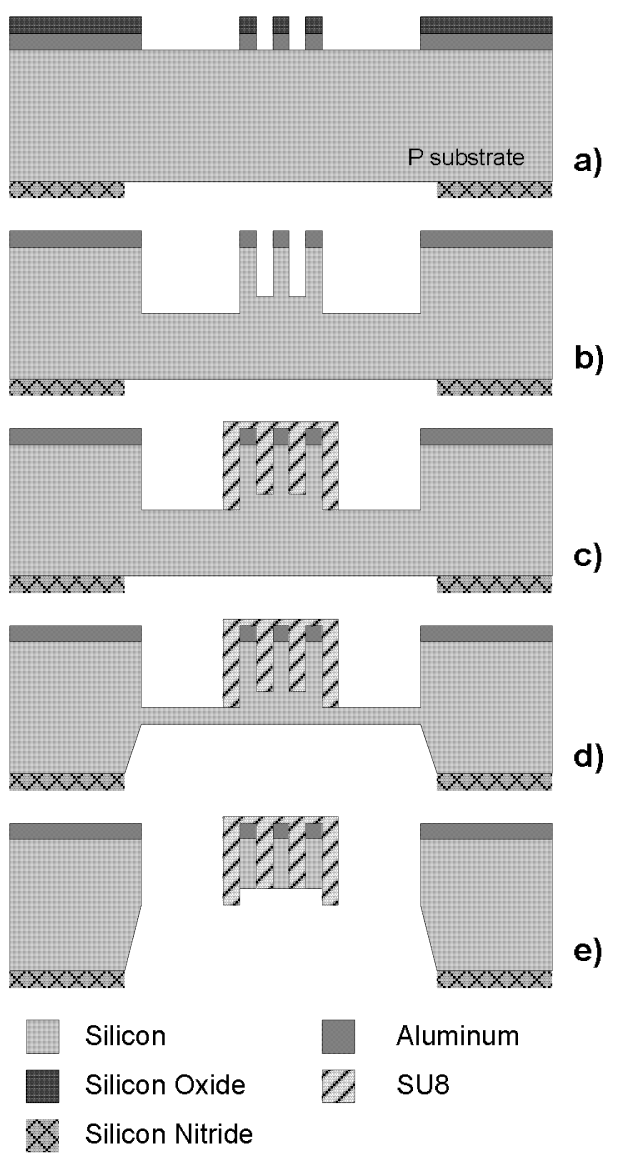

Figure 2. Schematic view of the fabrication process

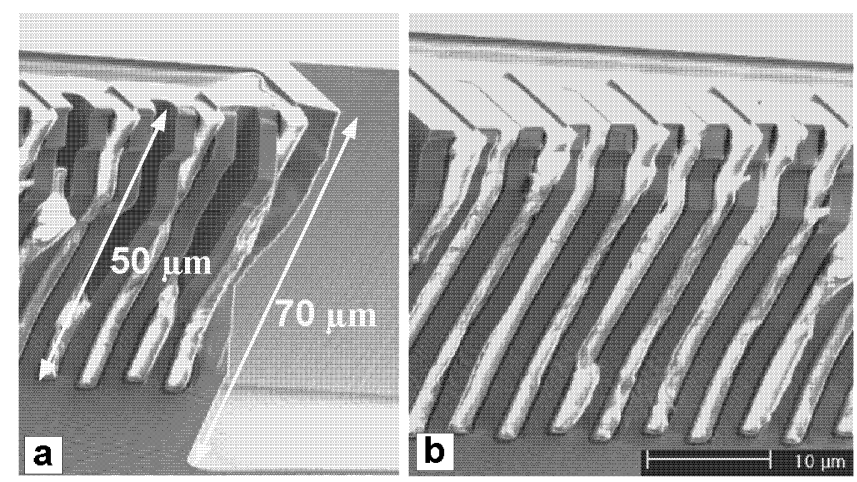

Figure 3. SEM pictures after deep RIE etching and SU8-2002 filling: a) the two depths achieved in a single deep RIE etch step and b) the void-free filling of the trenches by SU8-2002. 
Finally, the bulk silicon is etched from the back side in a $33 \mathrm{wt} \% \mathrm{KOH}$ solution at $85{ }^{\circ} \mathrm{C}$ until the thickness of the membrane outside the microgripper structures is about 10 $\mu \mathrm{m}$ (see Fig. 2d). The front side of the wafer is protected during the etching in $\mathrm{KOH}$ by a vacuum holder. The last step is the release of the structure by dry etching the remaining silicon layer from the backside (see Fig. 2e).

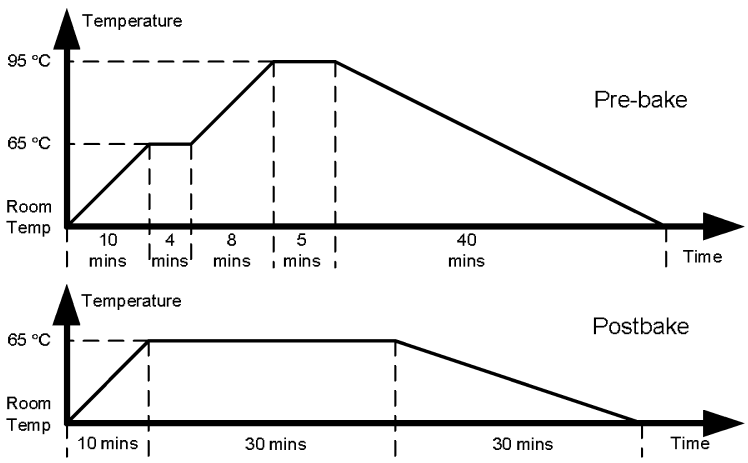

Figure 4. Experimental procedure for pre-bake and postbake of the SU8 polymer.

\section{RESUlts AND Discussions}

Fig. 5 shows the SEM pictures of the fabricated electrothermal integrated silicon-polymer laterally stacked microgripper. The actuators are $500 \mu \mathrm{m}$ long, $65 \mu \mathrm{m}$ wide and $50 \mu \mathrm{m}$ high. The geometry of the structure is shown in more detail in the close-up image.

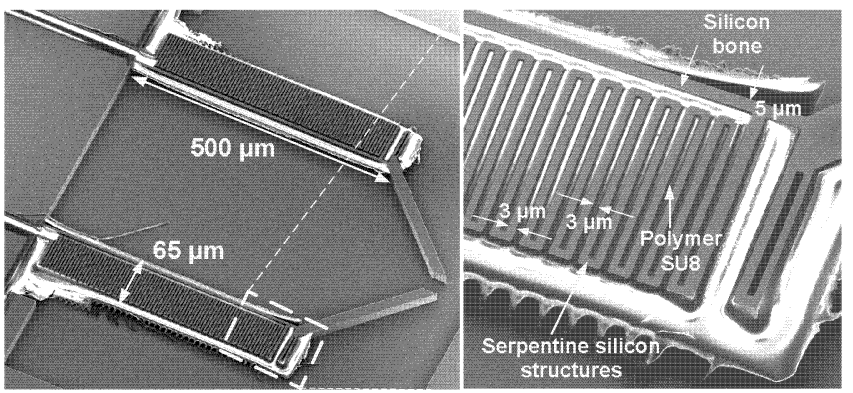

Figure 5. SEM pictures of the fabricated electro-thermal integrated silicon-polymer laterally stacked microgripper.

The structures are measured by using the Cascade microtech probe station [13] with built-in microscope component. Static displacement of the microgripper, activated by a DC voltage, is measured under an optical microscope. Fig. 6 shows images of some typical positions of the microgripper jaws. The microgripper is controlled by employing two DC voltages (see Fig. 6a). Fig. $6 \mathrm{~b}$ shows the initial position of the microgripper jaws. The gap between the two jaws is $40 \mu \mathrm{m}$. The distance between two jaws is closed to $24 \mu \mathrm{m}$ when applying a voltage of $1.25 \mathrm{~V}$ to both arms, see Fig. 6c. The two jaws touch each other if the applied voltage to both arms is larger than $1.8 \mathrm{~V}$. The jaws break each other when the applied voltage is further increased (see Fig. 6e and 6f). These pictures show that the generated force of the microgripper is strong enough to break the silicon tip.

Fig. 7 shows the movement of the microgripper jaws versus the applied voltage in air. This measured movement is the total change between the two microgripper jaws positions when both arms are activated. A maximum movement of 26 $\mu \mathrm{m}$ for one jaw is measured at a $2 \mathrm{~V}$ applied voltage. In principle a total change between jaws up to $52 \mu \mathrm{m}$ at $2 \mathrm{~V}$ could be obtained. However, in the design presented here, the initial gap between the two jaws is $40 \mu \mathrm{m}$ and the jaws are broken when applying $2 \mathrm{~V}$ to both arms. Thus the effective range of movement of this system is $40 \mu \mathrm{m}$.
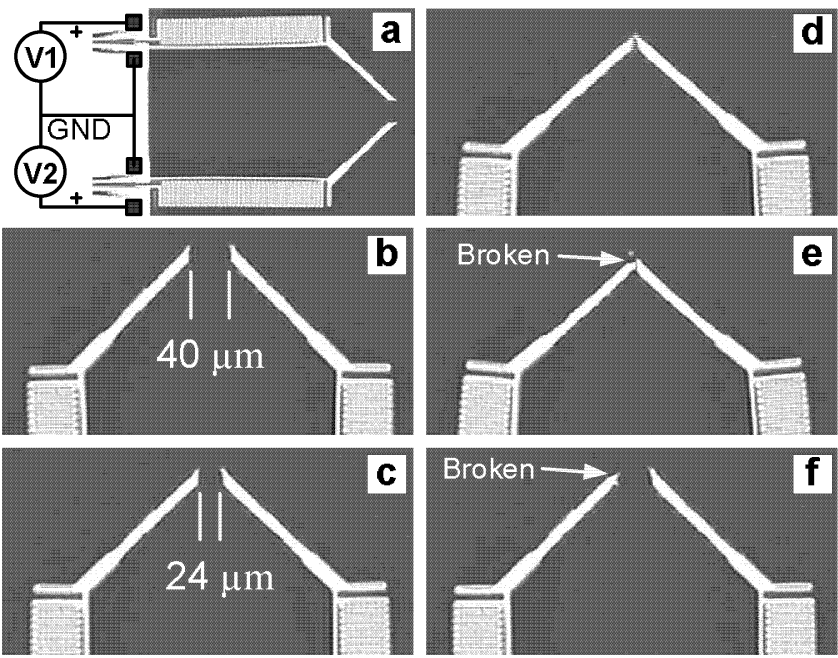

Figure 6. The device operation: a) the electronic setup; b) initial position of microgripper jaws, the distance between the two jaws is $40 \mu \mathrm{m}$; c) microgripper jaws when applying $1.25 \mathrm{~V}$ to both arms; d) microgripper jaws when applying $1.8 \mathrm{~V}$ to both arms, the distance between two jaws is zero; e) the jaws are broken when applying $2 \mathrm{~V}$ to both arms; f) the broken jaws when the voltage is switched off.

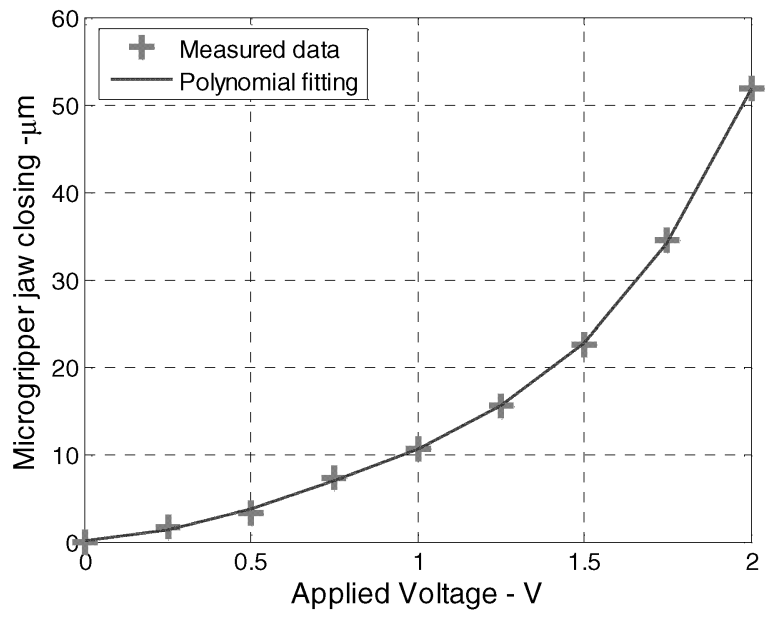

Figure 7. The microgripper jaws movement versus applied voltage. The maximum movement is $52 \mu \mathrm{m}$ at $2 \mathrm{~V}$ 
The power consumption is calculated through the applied voltage and the corresponding current. Fig. 8 shows the jaw movement versus the power consumption of the microgripper. The linear fitting line indicates that the device needs about $1 \mathrm{~mW}$ for a $1 \mu \mathrm{m}$ movement.

The working temperature of the actuator is determined by monitoring the change of the resistance of the aluminum heater. Fig. 8 also shows the relation between the jaws movements versus the working temperature of the device. The maximum jaws movement of the microgripper is $52 \mu \mathrm{m}$ at $164{ }^{\circ} \mathrm{C}$.

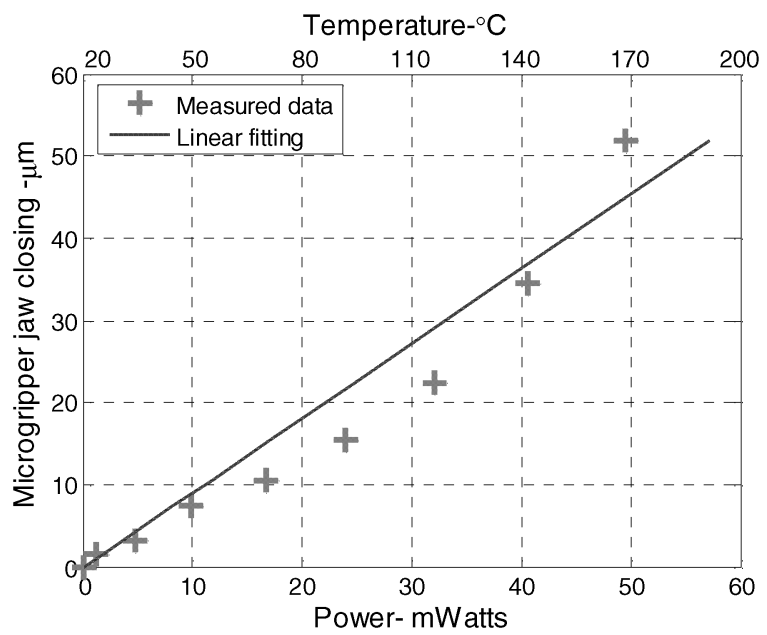

Figure 8. The microgripper jaws movement versus power consumption and working temperature. A movement up to $52 \mu \mathrm{m}$ at $164{ }^{\circ} \mathrm{C}$ is measured

This microgripper is working at a low driving voltage and at a low temperature. The gap between the two jaws can be controlled from zero to $40 \mu \mathrm{m}$. It is capable of grasping an object with a diameter from a few microns to $40 \mu \mathrm{m}$, the initial distance between the two jaws. The developed concept and process flow are such that it is possible to combine this microgripper with our developed lateral force sensing cantilever [8] to make a sensing microgripper. This structure can be used in application where the feedback force is essential. Moreover, this device is based on a biocompatible polymer.

\section{CONCLUSION}

A novel design of an electro-thermal microgripper based on integrated silicon-polymer laterally stacked microactuators is presented. A large movement up to $52 \mu \mathrm{m}$ at $2 \mathrm{~V}$ applied voltage is measured. The microgripper can be used to grasp objects with a diameter from a few microns to $40 \mu \mathrm{m}$. It consumes about $1 \mathrm{~mW}$ per $1 \mu \mathrm{m}$ movement. The maximum working temperature is $164{ }^{\circ} \mathrm{C}$ at $2 \mathrm{~V}$. The fabrication process is based on conventional bulk micromachining, polymer filling and is CMOS compatible. The proposed microgripper can potentially be used in bioassay as single cell manipulation and positioning, cell separation, minimally invasive, living cells surgery, microrobotics and microassembly.

\section{ACKNOWLEDGEMENTS}

The authors would like to acknowledge the whole DIMES IC Process group for technical support. We also would like to thank Dr. J.F.L. Goosen and Prof. F. van Keulen of the Precision and Microsystems Engineering Department for the many discussions. This work is partly sponsored by the Vietnamese Ministry of Education and Training.

\section{REFERENCES}

[1] S. Chonan, Z.W. Jiang, M. Koseki, "Soft-handling gripper driven by piezoceramic bimorph strips", Smart Mater. Struct. Vol. 5, pp. $407-$ 414, 1996.

[2] M.C. Carrozza, A. Menciassi, G. Tiezzi, P. Dario, "The development of a LIGA-microfabricated gripper for micromanipulation tasks", J.Micromech. Microeng. vol. 8, pp. 141-143, 1998.

[3] C.J. Kim, A. P. Pisano, R. S. Muller, "Silicon-processed overhanging microgripper", J. MEMS, vol. 1, no. 1, 1992.

[4] D. Yan, A. Khajepour, R. Mansour, "Modeling of two-hot-arm horizontal thermal actuator", J. Micromech. Microeng. vol. 13, pp. 312-322, 2004

[5] N. Chronis, L.P. Lee, "Electrothermally activated SU-8 microgripper for single cell manipulation in solution", J. MEMS, vol. 14, no. 4, pp. $857-863,2005$

[6] N.T. Nguyen, S. S. Ho, C.L.N. Low, "A polymeric microgripper with integrated thermal actuators", J. Micromech. Microeng. vol. 14, pp. 967-974, 2004

[7] J.W.L. Zhou, H.Y. Chan, T.K.H. To, K.W.C. Lai, and W.J. Li, "Polymer MEMS actuators for underwater micromanipulation", IEEE/ASME Trans. Mechatronics, vol. 9, no. 2, pp. 334-342, 2004.

[8] T. Chu Duc, J.F. Creemer, P.M. Sarro, "Lateral nano-Newton forcesensing piezoresistive cantilever for microparticle handling", J. Micromech. Microeng. vol. 16, no. 6, pp. 102-106, 2006.

[9] H. Lorenz, M. Laudon, P. Renaud, "Mechanical characterization of a new high-aspect-ratio near UV-photoresist," Microelectron. Eng., vol. 41-42, pp. 371-374, 1998

[10] L. Dellmann, S. Roth, C. Beuret, G.A. Racine, H. Lorenz, M Despont, P. Renaud, P. Vettiger, N.F. de Rooij, "Fabrication process of high aspect ratio elastic structures for piezoelectric motor applications," in Proc. Int. Conf. Solid-State Sens. Actuators, pp. 641-644, 1997.

[11] G. Voskericiana, M.S. Shivea, R.S. Shawgoc, H. von Recumd, J.M Andersona, M.J. Cimac, R. Langere, "Biocompatibility and biofouling of MEMS drug delivery devices", Biomaterials, vol 24, pp. 1959-1967, 2003

[12] http://www.suss.com/main.php?rad_id=351\&rad_f $=162$

[13] http://www.cascademicrotech.com/index.cfm/fuseaction/pg.view/pID 157 